\title{
LIBERACIÓN DE FÁRMACOS EN EL SEGMENTO POSTERIOR DEL OJO
}

\section{DRUG DELIVERY TO THE BACK OF THE EYE}

\author{
KOMPELLA UB ${ }^{1}$
}

La aprobación de los inhibidores del factor de crecimiento endotelial vascular (VEGF) Macugen ${ }^{\circledR}$ (2004) y Lucentis ${ }^{\circledR}$ (2006) por la Administración estadounidense de Fármacos y Alimentos (United States Food and Drug Administration) para el tratamiento de la degeneración macular asociada a la edad preparó el terreno para el desarrollo de numerosos agentes terapéuticos distintos, entre ellos el VEGF Trap, el VEGF siRNA y los inhibidores del receptor de la tirosin kinasa, para inhibir el VEGF y otros factores de crecimiento implicados en los trastornos de neovascularización retiniana. Recientemente, el receptor 2 de la esfingosina-1-fosfato (S1P2R) ha sido implicado en la angiogénesis retiniana patológica (1), indicando la potencial utilidad de los inhibidores del S1P2R en el tratamiento de los trastornos de neovascularización retiniana. Además, se ha demostrado que los péptidos de amiloide-beta están asociados al daño del nervio óptico, lo que sugiere la potencial utilidad de los fármacos anti-Alzheimer en el tratamiento del glaucoma con daño del nervio óptico (2). El ojo es el primer órgano para la introducción de los nuevos fármacos basados en ácidos nucleicos tales como los oligonucleótidos antisentido (Vitravene ${ }^{\circledR}, 1998$ ) y los aptámeros (Macugen). Potencialmente, también será el primer órgano para la aplicación de la terapia siRNA. Mientras que los nuevos objetivos proporcionan grandes oportunidades para el desarrollo de nuevos fármacos para el tratamiento de trastornos del polo posterior del ojo, una liberación segura, eficaz y cómoda para el paciente a lo largo de periodos prolongados frena el desarrollo de cualquier nuevo fármaco candidato.

Curiosamente, varios sistemas de liberación farmacológica innovadores fueron introducidos primero en aplicaciones oftalmológicas. Los ejemplos incluyen Ocusert ${ }^{\circledR}$ (1974), colocado en el fondo de saco conjuntival para la liberación constante de pilocarpina durante una semana; Vitrasert ${ }^{\circledR}$ (1996), colocado quirúrgicamente en el área de la pars plana del vítreo para la liberación constante de ganciclovir durante aproximadamente 6 meses; y Retisert $^{\circledR}$ (2005), más pequeño pero similar al Vitrasert para la liberación constante de acetónido de fluocinolona durante 2,5 años, por nombrar algunos. Un implante inyectable intravítreo, biodegradable, está actualmente en ensayos clínicos en fase III en Estados Unidos para el tratamiento del edema macular persistente. Este implante mantiene la liberación de dexametasona durante unas 5 semanas y los efectos durante 6 meses (Posurdex ${ }^{\circledR}$ ). Los implantes inyectables no degradables (Medidur ${ }^{\circledR}$ ) también están en desarrollo para mantener la liberación de fármaco durante algunos años. A pesar de los avances, todos los abordajes anteriores dirigidos al tratamiento del polo posterior del ojo precisan de la administración intravítrea. Algunos de los sistemas anteriores requieren de colocación y retirada quirúrgicas $\left(\right.$ Vitrasert $^{\circledR}$ y Retisert $\left.{ }^{\circledR}\right)$. Otros utilizan sistemas no degradables, inyectables, que podrían permanecer en el ojo durante años (Medidur ${ }^{\circledR}$ ). Todos los sistemas de liberación requieren administraciones repetidas con cierta frecuencia. Con dichas administraciones repetidas, las complicaciones asociadas al procedimiento, incluidas las cataratas, la endoftalmitis y el desprendimiento de retina, aumentan. De hecho, varios de los sistemas descritos, aunque eficaces, plantean cuestiones de seguridad debido al procedimiento de administración, al fármaco o al dispositivo.

La liberación transescleral a la parte posterior del ojo se considera una alternativa más segura que las inyecciones intravítreas repetidas (3). Esta vía, aunque más eficiente en la liberación de fármaco que las vías tópica o sistémica en general, es mucho

\footnotetext{
1 Profesor asociado y Científico distinguido. Farmacología y Oftalmología. Universidad del Centro Médico de Nebraska. Omaha. E-mail: ukompella@hotmail.com
} 
menos eficiente que la vía intravítrea para la liberación de fármacos a la retina. Modificaciones de los sistemas no degradables antes mencionados, diseñados para la liberación unidireccional de fármaco hacia la esclera son útiles para aumentar y mantener la liberación transescleral de medicamento. Una alternativa a los sistemas de liberación no degradables es el uso de nanopartículas y micropartículas biodegradables que llevan la droga necesaria encapsulada a la región periocular para la liberación transescleral (3). Tales sistemas no requieren colocación quirúrgica. Debido a su naturaleza degradable, no requieren extracción una vez que se ha completado la liberación del fármaco. Estos sistemas en concreto son especialmente útiles para fármacos que se aclaran rápidamente del sitio de administración. Mientras que partículas pequeñas de $20 \mathrm{~nm}$ se limpian rápidamente del sitio periocular donde se administraron, partículas de tamaño $200 \mathrm{~nm} \mathrm{y}$ mayores se mantienen durante periodos más prolongados y permiten una liberación transescleral mantenida de fármaco a la retina durante unos meses $(4,5)$. Los medicamentos con nanopartículas y micropartículas pueden ser preparados utilizando vehículos biodegradables tales como polímeros sintéticos, albúmina y lípidos (6). Sin embargo, es más difícil un control preciso de la liberación de fármaco a partir de estos sistemas durante periodos de tiempo prolongados.

En general, para la liberación mantenida de fármaco durante periodos prolongados, los sistemas de liberación de mayor tamaño son mejores que los más pequeños (es decir, los implantes no degradables son mejores que las micropartículas, que a su vez son mejores que las nanopartículas). Si el objetivo del tratamiento es aumentar la entrada celular de fármaco y si éste por sí mismo no tiene una penetración celular adecuada, las nanopartículas serían especialmente útiles (7). Los sistemas de nanopartículas, aunque son capaces de aumentar la liberación de moléculas poco permeables, pueden no aumentar la absorción de fármacos con buena permeabilidad. Sin embargo, pueden reducir el aclaramiento tanto de macromoléculas como de moléculas pequeñas desde el interior de células o tejidos. Cuando se administran tópicamente como colirio, la absorción corneal de incluso nanopartículas muy pequeñas es sólo del $2 \%$ debido al rápido aclaramiento precorneal (8). Curiosamente, con la funcionalización en superficie de nanopartículas con ligandos para receptores de la superficie celular, su absorción por la córnea puede incrementarse hasta un $16 \%$ en 5 min. Las nanopartículas funcionalizadas entran y cruzan la conjuntiva incluso mejor que la córnea. Queda por ver si tales nanopartículas funcionalizadas permiten una liberación del fármaco no invasiva a través de la conjuntiva y esclera al polo posterior del ojo en forma de colirio. A la larga, es más probable que los pacientes acepten mejor los abordajes no invasivos. Sin embargo, a menos que la entrada sistémica de los fármacos administrados en forma de colirio sea minimizada, los abordajes no invasivos podrían resultar en toxicidad sistémica, especialmente con la administración crónica.

Para ajustarse a los excitantes avances científicos en la identificación de objetivos nuevos con posibilidad de tratamiento farmacológico en el polo posterior del ojo, hay una gran necesidad de mejorar la liberación de fármacos al polo posterior del ojo. La tecnología de nanopartículas ofrece una posibilidad para mejorar la liberación no invasiva de fármacos al polo posterior ocular.

\section{BIBLIOGRAFÍA}

1. Skoura A, Sanchez T, Claffey K, Mandala SM, Proia RL, Hla T. Essential role of sphingosine 1-phosphate receptor 2 in pathological angiogenesis of the mouse retina. J Clin Invest 2007; 117: 2506-2516.

2. Guo L, Salt TE, Luong V, Wood N, Cheung W, Maass A, et al. Targeting amyloid-beta in glaucoma treatment. Proc Natl Acad Sci U S A 2007; 104: 13444-13449.

3. Raghava S, Hammond M, Kompella UB. Periocular routes for retinal drug delivery. Expert Opin Drug Deliv 2004; 1: 99-114.

4. Amrite AC, Kompella UB. Size-dependent disposition of nanoparticles and microparticles following subconjunctival administration. J Pharm Pharmacol 2005; 57: 1555 1563.

5. Amrite AC, Ayalasomayajula SP, Cheruvu NP, Kompella $U B$. Single periocular injection of celecoxib-PLGA microparticles inhibits diabetes-induced elevations in retinal PGE2, VEGF, and vascular leakage. Invest Ophthalmol Vis Sci 2006; 47: 1149-1160.

6. Marra M, Gukasyan HJ, Raghava S, Kompella UB. 2nd Ophthalmic Drug Development and Delivery Summit. Expert Opin Drug Deliv 2007; 4: 77-85.

7. Mo Y, Barnett ME, Takemoto D, Davidson H, Kompella UB. Human serum albumin nanoparticles for efficient delivery of $\mathrm{Cu}, \mathrm{Zn}$ superoxide dismutase gene. Mol Vis 2007; 13: 746-757.

8. Kompella UB, Sundaram S, Raghava S, Escobar ER. Luteinizing hormone-releasing hormone agonist and transferrin functionalizations enhance nanoparticle delivery in a novel bovine ex vivo eye model. Mol Vis 2006; 12: $1185-1198$. 